\title{
Mesh Sensitivity Study of Soil Barrier Subjected to Blast Loading: Numerical Methods Using AUTODYN 3D
}

\author{
Jestin $\mathrm{J}^{1}$, Faisal Ali ${ }^{1}$, Ahmad Mujahid Ahmad Zaidi ${ }^{2,3}$, Md Fuad Shah Koslan ${ }^{4}$ \& Mohd Zaid Othman ${ }^{2}$ \\ ${ }^{1}$ Department of Civil Engineering, Faculty of Engineering, Universiti Pertahanan Nasional Malaysia, Kuala \\ Lumpur, Malaysia \\ ${ }^{2}$ Department of Mechanical Engineering, Faculty of Engineering, Universiti Pertahanan Nasional Malaysia, \\ Kuala Lumpur, Malaysia \\ ${ }^{3}$ University College of Automotive, Pekan, Pahang, Malaysia \\ ${ }^{4}$ Royal Malaysian Air Force, Ministry of Defence, Kuala Lumpur, Malaysia \\ Correspondence: Jestin Jelani, Department of Civil Engineering, Faculty of Engineering, Universiti Pertahanan \\ Nasional Malaysia, Kuala Lumpur, Malaysia. Tel: 60-126-162-035. E-mail: at_tin009@yahoo.com
}

Received: January 3, 2014

doi:10.5539/mas.v8n6p250
Accepted: February 3, $2014 \quad$ Online Published: November 18, 2014

URL: http://dx.doi.org/10.5539/mas.v8n6p250

\begin{abstract}
The accuracy of numerical result depends on many factors, among which is the selection of appropriate element size. An optimum mesh size is capable in reducing the percentage error and computational time consumption. In this study, a numerical tool i.e AUTODYN 3D is used to determine the optimum element size for the soil barrier subjected to air blast load. The pressure results on barrier surface obtained through one third scale are able to produce results that are in good agreement with published experimental test data as compared to full scale simulation. In this study, the selection of mesh size $20 \mathrm{~mm}$ x $20 \mathrm{~mm}$ x $20 \mathrm{~mm}$ found considerably as the best element size for the case study of a rectangular soil barrier subjected to air blast load by using AUTODYN 3D software.
\end{abstract}

Keywords: AUTODYN 3D, mesh sensitivity, soil barrier, element size, convergence study

\section{Introduction}

There are three (3) well known techniques in determining the performance of structure and its behaviour when subjected to blast load namely empirical, semi empirical, and numerical methods. Numerical method is widely used in recent years (Chung et al. 2012, Zakrisson et al. 2011, Neuberger et al. 2009, Zhou et al. 2008, Uzair et al. 2013). By using numerical tools available nowadays, it has managed to assist researchers in minimising the number of experimental tests required and hence reduce the cost for investigation through physical blast experimental tests especially when the research involves development or parametric studies for a particular protective structure system.

In this study, the AUTODYN software developed by Century Dynamic (subsidiary of ANSYS Inc.) has been employed. AUTODYN is a hydrocode program which is suited to model interaction problem of different liquid, gas, and structure together in a single domain which uses either finite difference, finite volume, or finite element techniques to solve non-linear problem depending on what type of solver being used (Anderson, 1987). In modelling the blast phenomenon, a method known as spatial discretisation is used to divide the problem of interest into a finite system of nodes and elements. The fields and structures of the problem are represented by computational point in space and joined with each other through a computational grid. More accurate calculation will be produced by the smaller element size rather than courser element size which sacrifices accuracy for rapidity and simplicity in the calculation process (Bimbaum et al., 2003). AUTODYN allows different solvers (or processors) such as Lagrange and Euler to function simultaneously one simulation model analysis. The Euler solver for example, is usually used for representing fluids and gasses which typically suited to model expansion of gas product after detonation without having grid distortion problems (AUTODYN, 2010). Bimbaum et al (2003) described the numerical grid as fixed in space while the physical material which flows through the grid is typically well suited for the description of the material behaviour of severe deformation. Meanwhile, Langrange is considered as the most appropriate solver to represent solid continua like structure. Quan et al. (2003) 
described the Lagrange method of space discretisation as the numerical grid deformed with the material and is ideal for following the material motion and deformation.

The accuracy of using AUTODYN in predicting blast wave and structural behaviour has been investigated by many researchers. Remennikov (2003) made a comparison study between available analytical calculation in TM5-855-1 and AUTODYN software to predict blast load on a simple building structure. AUTODYN was able to give good prediction of the reflected impulse and arrival time during the positive phase at the building structure. Meanwhile, Yuen et al. (2013) carried out simplified numerical models using AUTODYN 3D and validated them with experiments for deflection analysis and the results showed encouraging correlation with experimental tests data.

It is well known that the accuracy of simulation results depends on selection of suitable solver to represent the materials, types of boundary condition, and the dimension of the model space. Apart from these factors, it is also influenced by the size of element. In this paper, mesh sensitivity will be studied to improve the accuracy of numerical results as performed by Andy (2010). Inaccuracy prediction of air blast pressure distribution on wall surface through simulation as compared to experimental test was due to insufficient refinement of finite element grid in the work (Andy, 2010). The problem arose when the simulation model was involved in large-scale distance where coarser element had to be used due to limited computer capacity.

The solution over large-scale distance can be obtained by utilising small scale model which will be discussed further in the next section. 3D Eulerian element sizes of $100 \mathrm{~mm} \times 100 \mathrm{~mm} \times 100 \mathrm{~mm}, 80 \mathrm{~mm} \times 80 \mathrm{~mm} \times 80$ $\mathrm{mm}$ and $20 \mathrm{~mm} \times 20 \mathrm{~mm} \times 20 \mathrm{~mm}$ will be used in order to analyse the effect of mesh sensitivity towards the final result. The pressure measurement on soil barrier surfaces from the experimental test results will be used as a reference in this study. The appropriate meshing sizes obtained could then be used for future simulation analysis. The numerical simulations work in the present study will be utilizing Intel core i7-3930K with $3.2 \mathrm{GHz}$ processor and $64 \mathrm{~Gb}$ of memory.

\section{Simulation Model}

In this study, simulation model was carried out to validate the field experimental tests performed by Andy (2010). In the field experimental tests, a rectangular geosynthetic reinforced soil wall known as Reinforced Soil Wall 1 (RSW1) with height, wide and thickness of $3 \mathrm{~m}, 6 \mathrm{~m}$ and $3 \mathrm{~m}$ respectively was subjected to blast load which was equivalent to $110 \mathrm{~kg}$ of trinitrotoluene (TNT) detonated on ground surface at $4 \mathrm{~m}$ distance away from the barrier, as shown in Figure 1. In the 3D simulation, only half of the wall was simulated in order to reduce the computational time. The 3D Euler and Lagrange size element selected in the study were of $100 \mathrm{~mm} \times 100 \mathrm{~mm} \times$ $100 \mathrm{~mm}$ and $200 \mathrm{~mm} \times 200 \mathrm{~mm} \times 200 \mathrm{~mm}$ respectively (see Figure 2a). The simulation results did not fit well with measured data and produced differences of up to $17 \%$ and $57 \%$ for peak pressure measurement at the front and rear wall surfaces respectively as shown in Figure $2 \mathrm{~b}$ and Table 1. In this paper, a new simulation model was developed to improve Andy's (2010) simulation results and the pressure measurement from experimental tests will be used as a reference and validation process.

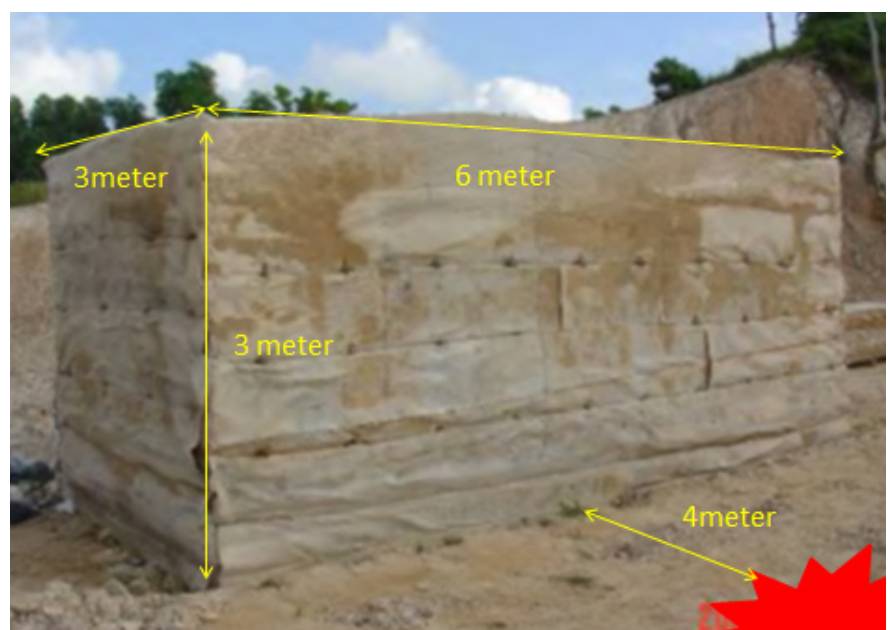

Figure 1. The Geosynthetic Reinforced Soil Wall 1, (RSW1) configuration in a full scale field blast testing (Andy, 2010) 


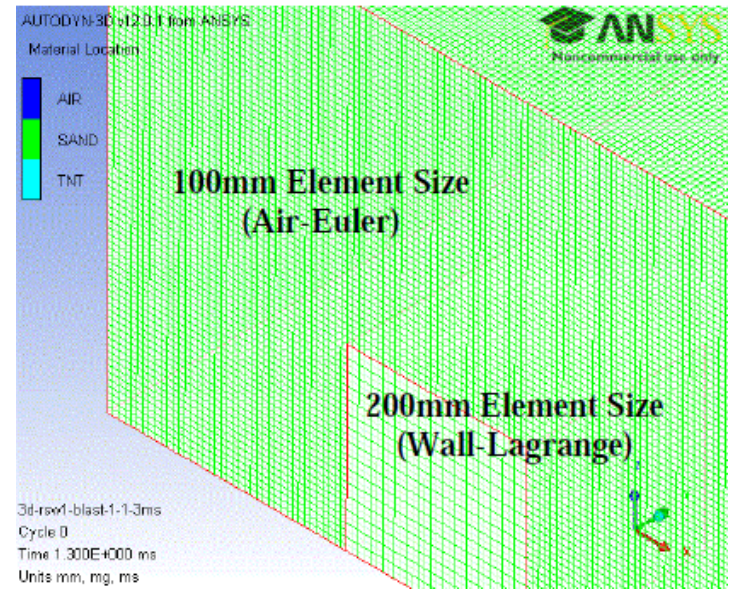

(a)

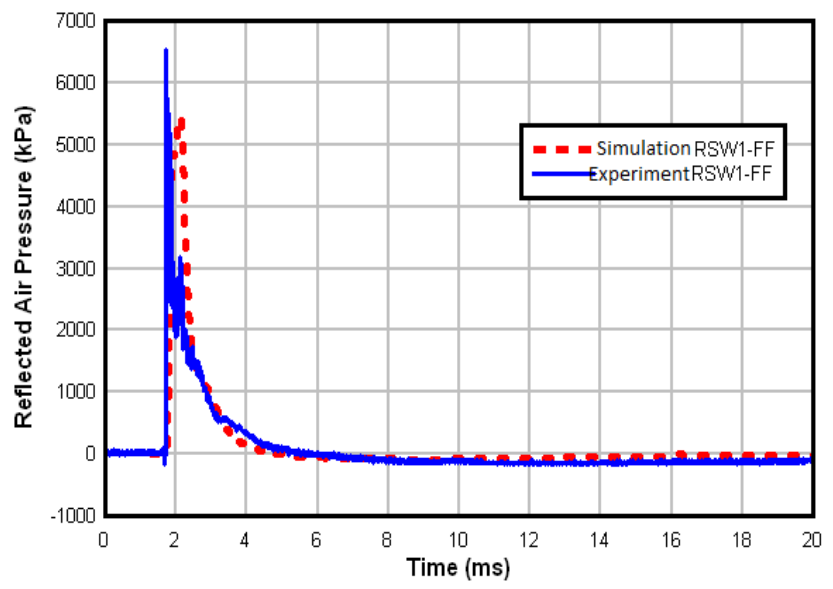

(b)

Figure 2. (a) Mesh sizes for Lagrange and Euler solver (b) Comparative result of experimental test and simulation for peak pressure at the middle front of wall surface (Andy, 2010)

Table 1. The results of field experimental test and simulation performed by Andy, (2010) for RSW1

\begin{tabular}{cccccccc}
\hline Type of analysis & $\begin{array}{c}\text { Scale } \\
\text { factor }\end{array}$ & $\begin{array}{c}\text { Weight of } \\
\text { TNT } \\
(\mathrm{kg})\end{array}$ & $\begin{array}{c}\text { Stand-off } \\
\text { Distance }(\mathrm{m})\end{array}$ & $\begin{array}{c}\text { Barrier } \\
\text { dimension } \\
(\mathrm{m})\end{array}$ & \multicolumn{2}{c}{ Results (kPa) } \\
\hline Experiment & Full & 110 & 4 & $6 \times 3 \times 3$ & 6539 & 932 & 115 \\
Simulation & Full & 110 & 4 & $6 \times 3 \times 3$ & 5450 & 904 & 49 \\
\hline
\end{tabular}

\subsection{Using Hopkinson-Cranz Scaling Law to Determine the Test Parameters of the New Simulation Model}

Blast scaling is used to relate physical dimensions between different charge weight and stand-off configuration to a previous test conducted with different charge weight and stand-off distance (Baker, 1973 and Smith, 1994). The commonly used scaling law is Hopkinson-Cranz scale (or cube-root) with stand-off distances and charge weight combined as a scaled distance and calculated using Eq (1)

$$
Z=\frac{R}{W^{\frac{1}{3}}}
$$

where $R$ is stand-off distance and $W$ is charge weight. The dimensions of computational model in this study have two scale sizes; full scale and one-third scale. In the full scale simulation, the dimensions of the charge weight and barrier were kept the same as experimental test dimension, but however in the one-third scale those sizes and dimensions are altered. Table 2 shows the mass of $2.97 \mathrm{~kg}$ of TNT for the $1.2 \mathrm{~m}$ stand-off distance to represent the blast loads which were similar to those produced by $110 \mathrm{~kg}$ TNT at $4 \mathrm{~m}$ away of barrier which poses same scaled distance 0.83. Apart from that, the height, wide, and thickness of RSW1 scaled to one-third resulted in a $900 \mathrm{~mm}$ x $1800 \mathrm{~mm}$ x $900 \mathrm{~mm}$ barrier dimension respectively.

Table 2. The summary of geometric and mass explosive scaling for RSW1

\begin{tabular}{|c|c|c|c|c|c|}
\hline Type analysis & $\begin{array}{l}\text { Scale } \\
\text { factor }\end{array}$ & $\begin{array}{c}\text { Weight of } \\
\text { TNT, } \\
\text { W } \\
(\mathrm{kg})\end{array}$ & $\begin{array}{c}\text { Stand-off } \\
\text { distance, } \\
\text { R } \\
(\mathrm{m})\end{array}$ & $\begin{array}{c}\text { Scaled } \\
\text { distance, } \\
Z \\
\left(\mathrm{~m} / \mathrm{kg}^{1 / 3}\right)\end{array}$ & $\begin{array}{c}\text { Barrier } \\
\text { dimension, } \\
\text { HxWxT } \\
(\mathrm{m})\end{array}$ \\
\hline Experiment (Andy, 2010) & Full & 110 & 4 & 0.83 & $3 \times 6 \times 3$ \\
\hline AUTODYN 3D Simulation & 0.3 & 2.97 & 1.2 & 0.83 & $0.9 \times 1.8 \times 0.9$ \\
\hline
\end{tabular}




\subsection{One Third Scale Computational Model}

The 3D domain size was $3500 \mathrm{~mm} \times 2000 \mathrm{~mm} \times 2000 \mathrm{~mm}$ at $\mathrm{x}, \mathrm{y}, \mathrm{z}$ axes respectively and defined as air. The model had been set to be symmetrical at x-z-plane and therefore, only a quarter of symmetry hemispherical charge and half-columns were simulated in order to reduce the computational time. The 1D and 3D computational models are as shown in Figure $3 \mathrm{a}$ and $3 \mathrm{~b}$ respectively. The transmit boundary condition was applied at 4 sides of domain to enable the air pressure flowing out without being reflected back inside into the main blast domain. At the bottom of soil barrier, velocity was kept at $0 \mathrm{~m} / \mathrm{s}$ to simulate fixed boundary condition. It means that the barrier will act as a flexible cantilever beam and no displacement will occur at the bottom of soil barrier as the ground was assumed to be highly compacted. In the 1D wedge model, the multi material Euler solver was used to represent air and TNT. In the 3D model, air space was modelled as Euler solver while soil barrier was defined as Lagrange solver. An important factor that one needs to consider was the type of interaction between Lagrange and Euler solvers (or Euler/Lagrange coupling). In this paper a 'Fully coupled' interaction was chosen for the simulation model. Pressure gauges (red colour) were placed at the middle front face, side, and middle back surface of barrier to measure the reflected and diffracted pressure waves as shown in Figure $3 \mathrm{~b}$.

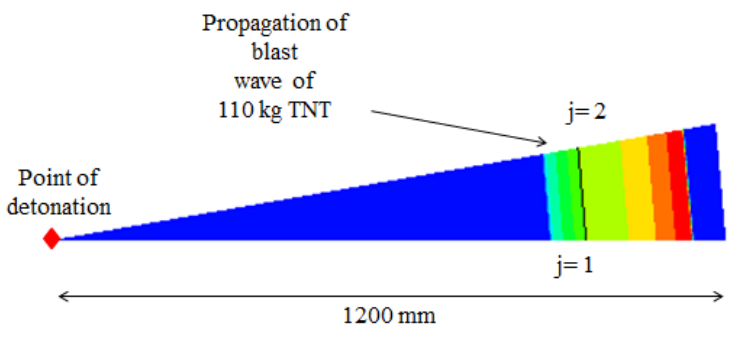

(a)

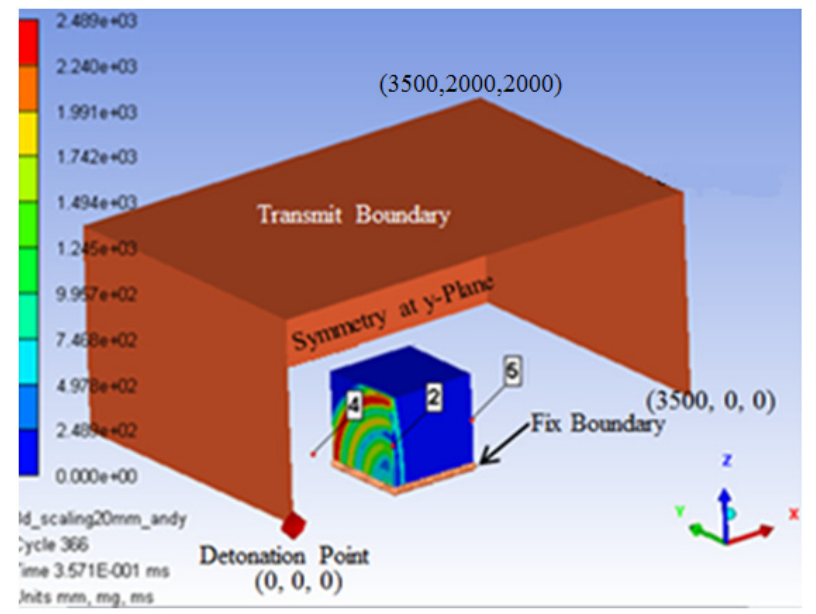

(b)

Figure 3. (a) The 1D spherically symmetric AUTODYN 2D model for mapping into AUTODYN 3D (b) The 3D domain model setup

\subsection{Modifications on TNT Weight in 1D Wedge Model}

In the 1D wedge model, TNT was modelled as a spherical burst. The default density of TNT $\left(\rho_{\mathrm{TNT}}=1630 \mathrm{~kg} / \mathrm{m}^{3}\right)$ was used to calculate the radius of a $110 \mathrm{~kg}$ (full scale) and $3 \mathrm{~kg}$ (one third scale) spherical charge of TNT that resulted in $252.6 \mathrm{~mm}$ and $76 \mathrm{~mm}$ respectively. However, in an actual case, the charge detonated on ground surface produced hemispherical burst. Therefore, some modification had to be made on the TNT calculation for the 1D model. In order to simulate the actual hemispherical blast, the actual equivalent TNT charge weight is multiplied by a factor of 1.8 because of the reflection from the ground and the energy lost from the formation of crater (Remennikov, 2003). The modified TNT radiuses for the full and one third scale now were $307.2 \mathrm{~mm}$ and $92.2 \mathrm{~mm}$ respectively.

\subsection{Mapping Techniques}

AUTODYN has a unique capability to map a solution from a 1D detonation calculation to a 2D axis symmetry computational domain as shown by Chapman et al. (1995). In this study, the technique of mapping result from $1 \mathrm{D}$ to $3 \mathrm{D}$ in the Eulerian domain will be demonstrated. Mapping was done in order to reduce the computational time. In the initial steps, the 1D spherically symmetric wedge model was constructed as shown in Figure 3a (consisting of air and explosive only). The length of the 1D wedge model was taken from the stand-off distance between the charge and the barrier, in this case was $1200 \mathrm{~mm}$. The element sizes in 1D can be used as small as $1 \mathrm{~mm}$, rather than its corresponding 3D model which was much coarser. In the 1D model, the waves propagate until it almost reached the boundary and then the file was saved as '*.fil' format. In the second step, the result was rotated to correspond x-axis and mapped onto AUTODYN 3D to fill the Eulerian domain as an initial condition. 


\subsection{Material Model}

\subsubsection{Properties of Detonation}

The explosive detonation and expansion were modelled by using Jones-Wilkins-Lee (JWL) equation of state (EOS) for TNT and the equation is given by

$$
P=C_{1}\left(1-\frac{\omega}{R_{1} V}\right) e^{-R_{1} V}+C_{2}\left(1-\frac{\omega}{R_{2} V}\right) e^{-R_{2} V}+\frac{\omega E}{V}
$$

Where $P$ is the hydrostatic pressure, $\mathrm{C}_{1}, \mathrm{C}_{2}, \mathrm{R}_{1}, \mathrm{R}_{2}$ and $\omega$ empirically derived constant which provides different constant values for different explosives; $\mathrm{V}$ is the specific volume of detonation product over the specific volume of undetonated explosive and $\mathrm{E}$ is specific internal energy. The detonation model in this study had been converted into an equivalent of $110 \mathrm{~kg}$ TNT and the model is already available in AUTODYN library where the value of $\mathrm{C}_{1}, \mathrm{C}_{2}, \mathrm{R}_{1}, \mathrm{R}_{2}$ and $\omega$ are $3.7377 \times 10^{8} \mathrm{MPa}, 3.7471 \times 10^{6} \mathrm{MPa}, 4.15,0.9$ and 0.35 respectively.

\subsubsection{Properties of Air}

Air was modelled as Ideal Gas equation of state as shown in Eq (3).

$$
P=(\gamma-1) \rho E
$$

Where $P$ is the pressure, $\gamma$ is the adiabatic constant and is equal to $1.4, \rho$ is the air density and is equal to 1.225 $\mathrm{kg} / \mathrm{m}^{3}$ and $\mathrm{E}$ is the specific air internal energy $2.068 \times 10^{5} \mathrm{~kJ} / \mathrm{kg}$.

\subsubsection{Soil Properties}

The soil's EOS was derived based on tri-axial test conducted by Laine and Sandvik (2001) on medium to coarse sand from southern part of Sweden which was described by plastic compaction curve from the polynomial function of pressure-density as shown in Figure 4. The data was implemented in AUTODYN where compaction curve for pressure above $60 \mathrm{MPa}$ was predicted using a polynomial best fit of fifth order. The soil's failure model was named as Hydro Tensile Failure Model where the soil was considered fail when the minimum pressure value, Pmin $=-1 \times 10-3$ Pa was reached (Laine and Sandvik, 2001).

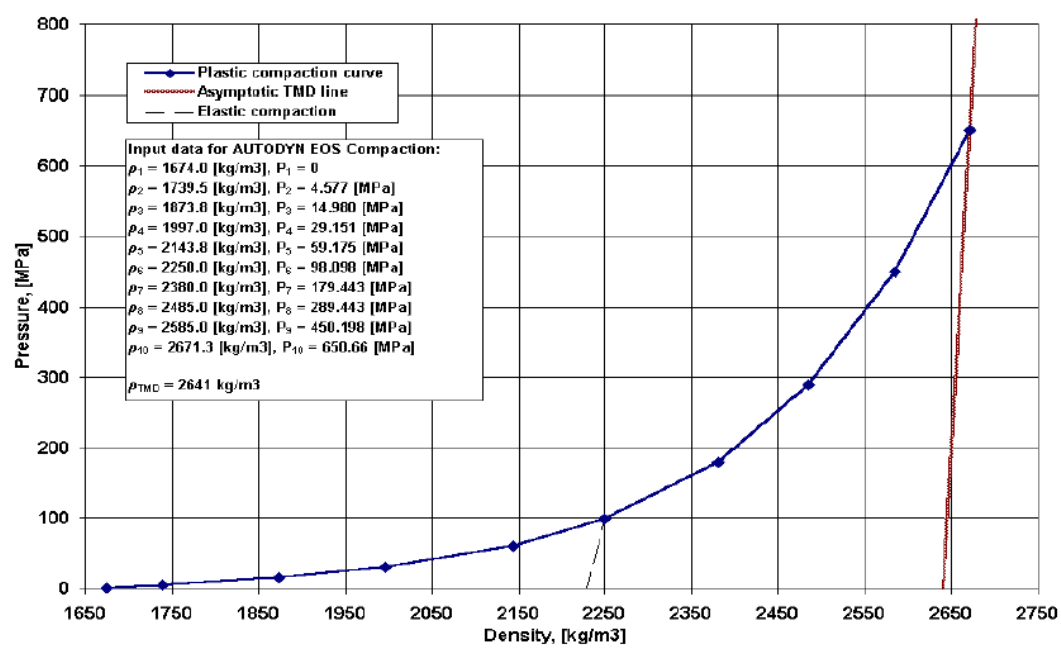

Figure 4. The input data of EOS of compaction sand in AUTODYN material library (Laine and Sandvik, 2001)

\section{Results and Discussion}

The details of the simulation results are tabulated in Table 3. The simulations were performed in full scale and one third scale in order to study the mesh sensitivity and validate the accuracy of numerical result through the experimental field test. The $20 \mathrm{~mm} \times 20 \mathrm{~mm} \times 20 \mathrm{~mm}$ element size was not possible to run in full scale domain due to inadequacy of computer's memory capacity and therefore only one third-scale was attempted.

As depicted in Figure 5, for example, an $80 \mathrm{~mm}$ x $40 \mathrm{~mm}$ line denotes $80 \mathrm{~mm}$ and $40 \mathrm{~mm}$ element size was used for Euler and Langrange in 3D model respectively. The pressure measurements converged to field data when the element size for Euler and Lagrange was small at $20 \mathrm{~mm}$. This was the smallest size enough to obtain converged result which took computation time of almost 10 hours to complete. The computations with $5 \mathrm{~mm}$ finer will 
generate around 4 million elements and that was beyond the capability of this computer. This was the smaller size enough to obtain less than $10 \%$ error and it is worth to get such result in 10 hours waiting to avoid $8.2 \%$ to $33 \%$ error.

The percentage of differences can be seen in Figure 6, in which Test 3 gave the lowest value of approximately less than $10 \%$, which the element size was $20 \mathrm{~mm}$. It can be concluded that by using scaling, not only the element sizes are reduced, but also increased simulation accuracy, reduces the number of element utilised in this analysis; even not too much differences, and subsequently reduce computational time as well. It is suggested that, if large range in scaled distance involved in a particular problem, Hopkinson-Cranz blast scaling law is an alternative method to accurately simulate blast pressure involving large range of scale domain.

Table 3. Comparative results for the full and one third scale of soil barrier

\begin{tabular}{|c|c|c|c|c|c|c|c|c|c|}
\hline \multirow[t]{2}{*}{ Test } & \multirow{2}{*}{$\begin{array}{c}\text { Element size } \\
\text { in 3D model } \\
\text { (Euler / } \\
\text { Lagrange) }\end{array}$} & \multirow{2}{*}{$\begin{array}{c}\text { Numbers of } \\
\text { element } \\
\text { (million) }\end{array}$} & \multirow{2}{*}{$\begin{array}{l}\text { Type of } \\
\text { analysis }\end{array}$} & \multirow{2}{*}{$\begin{array}{l}\text { Scale } \\
\text { factor }\end{array}$} & \multicolumn{3}{|c|}{ Gauge Reading $(\mathrm{kPa})$} & \multirow{2}{*}{$\begin{array}{c}\% \text { difference } \\
\text { pressure at } \\
\text { front/side/rear of } \\
\text { wall face }\end{array}$} & \multirow{2}{*}{$\begin{array}{c}\text { Time } \\
\text { taken } \\
(\mathrm{hr})\end{array}$} \\
\hline & & & & & Front & Side & Rear & & \\
\hline (Andy, 2010) & - & - & Field & Full & 6539 & 932 & 115 & $0 / 0 / 0$ & - \\
\hline (Andy, 2010) & $100 / 200$ & 1.2 & Simulation & Full & 5450 & 904 & 49 & $17 / 3 / 57$ & - \\
\hline Test 1 & $100 / 100$ & 1.2 & Simulation & Full & 5453 & 643 & 153 & $16.6 / 28 / 33$ & 8 \\
\hline Test 2 & $80 / 40$ & 1.76 & Simulation & Full & 6003 & 813 & 126 & $8.2 / 13 / 9.5$ & 11 \\
\hline Test 3 & $20 / 20$ & 1.75 & Simulation & 0.3 & 6578 & 840 & 127 & $0.6 / 9.9 / 10$ & 10 \\
\hline
\end{tabular}

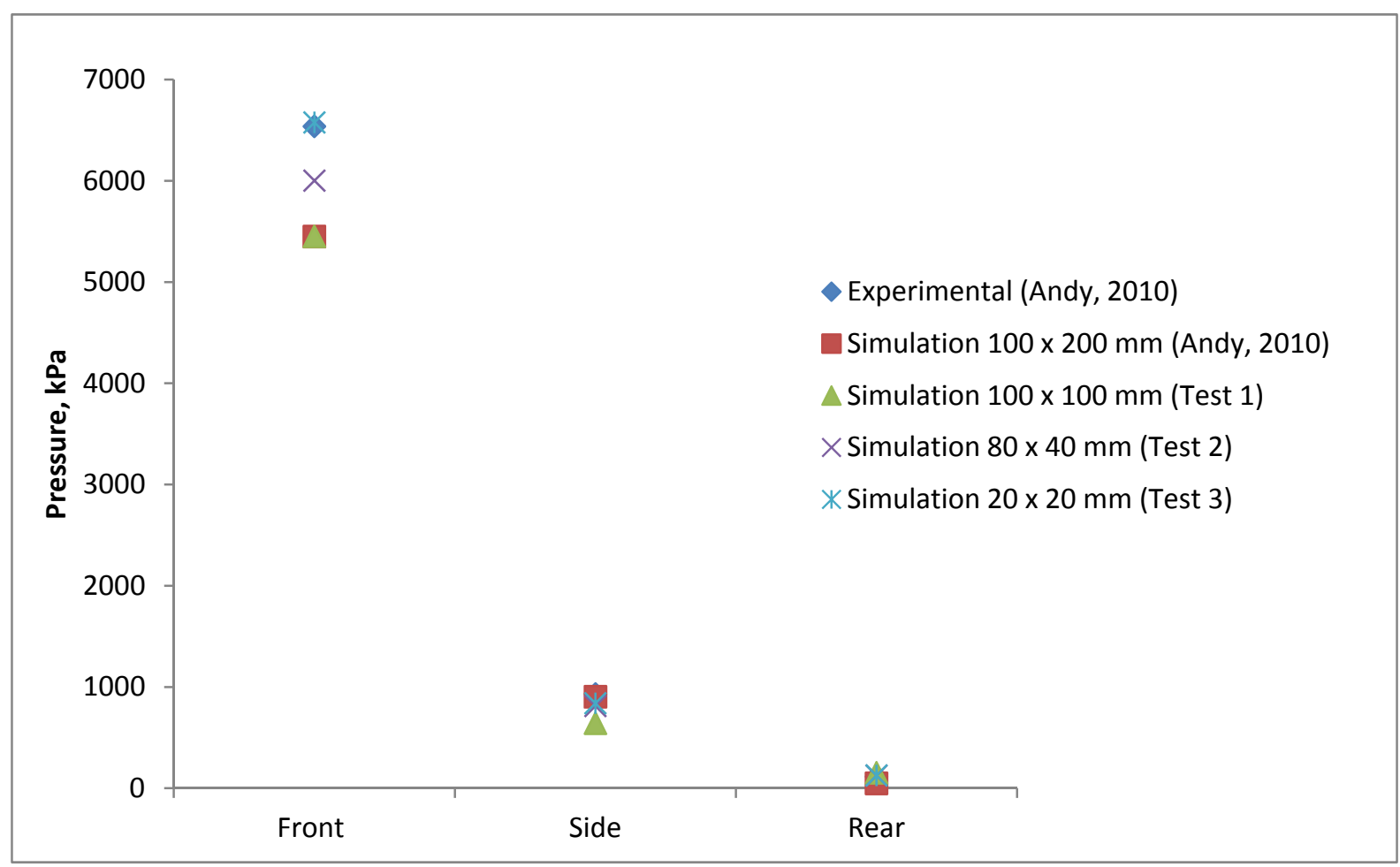

Figure 5. The results of the convergence study on barrier surface. The comparison between experimental test and simulation results for various element sizes 


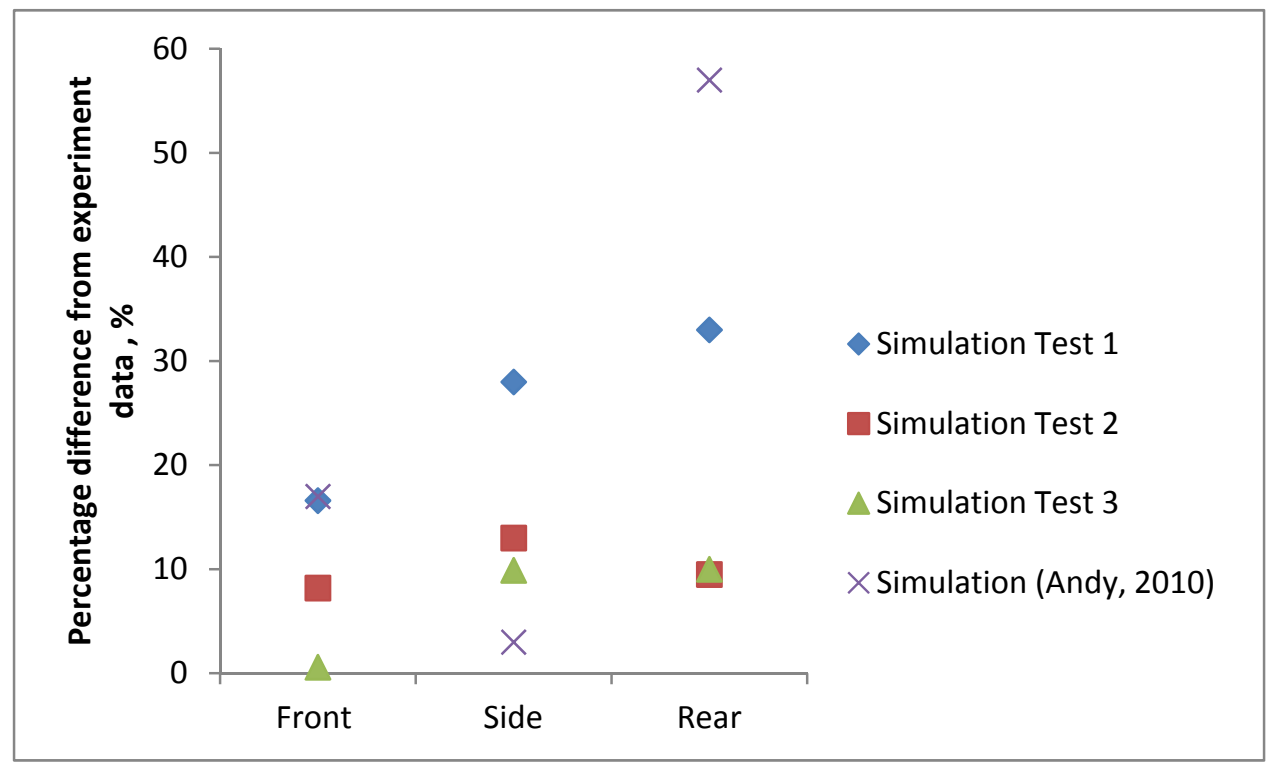

Figure 6. Percentage of errors on barrier surface of different simulation tests

\section{Conclusions}

The selection of mesh sizes was found to be one of the factors to determine the accuracy of the results produced. Common error occurs in simulation analysis was due to the insufficient refinement of finite element grid. The problem arises when the simulation model involved in large domain where coarser element has to be used due to limited computer capacity.

The solution over large domain size can be obtained by utilising small scale model. Result shows that as the element sizes become smaller, the accuracy of analysis and simultaneously the computational time increase. In this case, the selection of mesh size $20 \mathrm{~mm} \times 20 \mathrm{~mm} \times 20 \mathrm{~mm}$ found considerably as the best element size that produce good agreement with the experimental data for front pressure measurement. Meanwhile, for side and rear pressure measurement, it still gives lower percentage of difference for the rectangular soil barrier subjected to air blast load by using AUTODYN 3D software.

\section{Acknowledgements}

The authors appreciate the financial support for the work from the Ministry of Higher Education of Malaysia under ERGS grant no. ERGS/1/2012/PK04/UPNM/01/2.

\section{References}

Anderson, C. E. (1987). An overview of the theory of hydrocodes. International Journal of Impact Engineering, 5, 33-59. http://dx.doi.org/10.1016/0734-743X(87)90029-7

Andy, T. H. W. (2010). Reinforced soil walls for mitigation of close range blast loading. PhD thesis. National University of Singapore.

Baker, W. E. (1973). Explosions in Air. University of Texas Press, Austin, Texas.

Birnbaum, N. K., Nigel, J. F., \& Bence I, G. (2003). Coupled techniques for the simulation of fluid-structure and impact problem. Century Dynamic. Inc2003. Retrieved from http://hsrlab.gatechedu/ AUTODYN/papers/paper63.pdf

Chapman, T. C., Rose, T. A., \& Smith, P. D. (1995). Blast wave simulation using AUTODYN2D: A parametric $\begin{array}{llllll}\text { study. International Journal of Impact Engineering, } & 16, & \text { 777-787. }\end{array}$ http://dx.doi.org/10.1016/0734-743X(95)00012-Y

Chung, K. Y. S., Langdon, G. S., Nurick, G. N., Pickering, E. G., \& Balden, V. H. (2012). Response of V-shape plates to localised blast load: Experiments and numerical simulation. International Journal of Impact Engineering, 46, 97-109. http://dx.doi.org/10.1016/j.ijimpeng.2012.02.007

Introduction to ANSYS AUTODYN. (2010). User training manual. Century Dynamics Inc.

Laine, L., \& Sandvik, A. (2001). Derivation of mechanical properties for sand. Proceedings of 4th Asia-Pacific 
Conference on shock \& impact loads on structures (pp. 361 -368), Singapore. CI-Premier Ltd.

Neuberger, A., Peles, S., \& Rittel, D. (2009). Springback of circular clamped armour steel plates subjected to spherical air-blast loading. International Journal of Impact Engineering, 36, 53-60. http://dx.doi.org/10.1016/j.ijimpeng.2008.04.008

Quan, X., Birnbaum, N. K., Cowler, M. S., Gerber, B. I., Clegg, R. A., \& Hayhurst, C. J. (2003). Numerical simulation of structural deformation under shock and impact loads using a coupled multi-solver, 5th Asia-Pacific Conference on Shock and Impact Load on Structures.

Remennikov, A. M. (2003). A review of methods for predicting bomb blast effects on buildings. Journal of Battlefield Technology, 6, 5-10.

Smith, P. D., \& Hetherington, J. G. (1994). Blast and ballistic loading of structures. Oxford, Butterworth-Heinemann Ltd.

Uzair, A. D., Zhang, W., \& Xu, Y. (2013). FE analysis of dynamic response of aircraft wind shield against bird impact. International Journal of Aerospace Engineering. ID 171768.

Zakrisson, B., Wikman, B., \& Häggblad, H. A. (2011). Numerical simulations of blast loads and structural deformation from near-field explosions in air. International Journal of Impact Engineering, 38, 597-612. http://dx.doi.org/10.1016/j.ijimpeng.2011.02.005

Zhou, X. Q., \& Hao, H. (2008). Prediction of air blast loads on structures behind a protective barrier. International Journal of Impact Engineering, 35, 363-375. http://dx.doi.org/10.1016/j.ijimpeng.2007.03.003

\section{Copyrights}

Copyright for this article is retained by the author(s), with first publication rights granted to the journal.

This is an open-access article distributed under the terms and conditions of the Creative Commons Attribution license (http://creativecommons.org/licenses/by/3.0/). 